\title{
Aggregation and Ionization Equilibria of Bis(pentafluorophenyl)borinic Acid Driven by Hydrogen-Bonding with Tetrahydrofuran
}

\author{
Tiziana Beringhelli, ${ }^{\S}$ Giuseppe D’Alfonso, ${ }^{*}, \S$ Daniela Donghi, ${ }^{\S}$ Daniela Maggioni, ${ }^{\S}$ \\ Pierluigi Mercandelli, ${ }^{*}{ }^{\dagger}$ and Angelo Sironi ${ }^{\dagger}$ \\ Dipartimento di Chimica Inorganica, Metallorganica e Analitica and Dipartimento di Chimica Strutturale \\ e Stereochimica Inorganica, Universita di Milano, Via Venezian 21, 20133 Milano, Italy
}

Received December 21, 2006

\begin{abstract}
Bis(pentafluophenyl)borinic acid, $\mathrm{Ar}_{2} \mathrm{BOH}\left(\mathbf{1}, \mathrm{Ar}=\mathrm{C}_{6} \mathrm{~F}_{5}\right)$, in dichloromethane solution is present as an equilibrium mixture of monomeric $\left(\mathbf{1}_{\mathbf{m}}\right)$ and trimeric $\left(\mathbf{1}_{\mathbf{t}}\right)$ forms. Previous studies showed that water affects both the position and the rate of this equilibrium. Here, the behavior of $\mathbf{1}$ in the presence of tetrahydrofuran (THF), a nucleophile able to behave as a Lewis base and H-bond acceptor only, has been studied, by monitoring with ${ }^{1} \mathrm{H}$ and ${ }^{19} \mathrm{~F}$ NMR the course of titrations performed directly into NMR tubes. The addition, at $183 \mathrm{~K}$, of 0.33 equiv of THF caused the instantaneous and quantitative formation of the hydrogen-bonded adduct between the trimer $\mathbf{1}_{\mathbf{t}}$ and one molecule of THF. Homo- and heteronuclear 2D NMR correlation experiments led to a solution structure consistent with the $C_{2}$-optimized geometry obtained by PM3 computations. The H-bonding of the THF molecule causes major deformations of the molecular geometry of the trimer, so that only one molecule of THF can interact with the trimer, in spite of its three $\mathrm{OH}$ groups. Intra- and intermolecular exchange processes involving this adduct have been investigated by 2D EXSY experiments, showing flopping of the cycle conformation, rotation of the aromatic rings around their $\mathrm{B}-\mathrm{C}$ bonds, and exchange of THF among the three $\mathrm{OH}$ groups, in addition to the exchange between free $\mathbf{1}_{\mathbf{t}}$ and the adduct. When the amount of added THF was higher than 0.33 equiv, an unexpected ionization process occurred, leading to the cation $\left[\mathrm{Ar}_{2} \mathrm{~B}\left(\mathrm{OH}_{2}\right)_{2}\right]^{+}$ and to deprotonated $\mathbf{1}_{\mathbf{t}}$, i.e., to the anion $\left[\mathrm{Ar}_{6} \mathrm{~B}_{3} \mathrm{O}_{3} \mathrm{H}_{2}\right]^{-}$of $C_{s}$ symmetry. On increasing the temperature, progressive partial fragmentation of the trimeric species was observed. Both ${ }^{11} \mathrm{~B}$ NMR evidence and PM3 computations indicated that, at variance with what is observed in the interaction with $\mathrm{H}_{2} \mathrm{O}$, the interaction between THF and $\mathbf{1}_{\mathbf{m}}$ occurs preferentially via an $\mathrm{H}$-bonded adduct, $\mathrm{Ar}_{2} \mathrm{BO}-\mathrm{H} \cdots \mathrm{THF}$, rather than a Lewis acid-base complex, $\mathrm{Ar}_{2} \mathrm{~B}(\mathrm{OH})(\mathrm{THF})$. This confirms the poor Lewis acidity of the boron atom of $\mathbf{1}_{\mathrm{m}}$.
\end{abstract}

\section{Introduction}

The organometallic chemistry of boron is a subject of high current interest, ${ }^{1}$ due to the variety of applications that organoboron derivatives have found in synthesis and catalysis. The behavior of these molecules still shows many intriguing aspects and calls for detailed basic studies on their reactivity and structural features. The title compound, bis(pentafluorophenyl)borinic acid, $\left(\mathrm{C}_{6} \mathrm{~F}_{5}\right)_{2} \mathrm{BOH}(\mathbf{1}$, hereafter simply borinic acid), is paradigmatic from this point of view. Recently, it has been the object of intense investigations, both from academia and industry. ${ }^{2-6}$ This is attributable to the fact that, in spite of its simplicity, $\mathbf{1}$ can be involved in a variety of intermolecular

* Corresponding authors. E-mail: giuseppe.dalfonso@unimi.it; pierluigi.mercandelli@unimi.it.

$\S$ Dipartimento di Chimica Inorganica, Metallorganica e Analitica.

† Dipartimento di Chimica Strutturale e Stereochimica Inorganica.

(1) (a) Burkhardt, E. R.; Matos, K. Chem. Rev. 2006, 106, 2617. (b) Hall, D. G. Boronic Acids; Wiley-VCH: Weinheim, 2005. (c) Smith K. Organoboron Chemistry. In Organometallics in Synthesis; Manual, A., Schlosser, M., Eds.; Wiley: Chichester, 2002. (d) King, R. B., Ed. Boron Chemistry at the Millennium. J. Organomet. Chem. 1999, 581, 1. (e) Piers, W. E.; Chivers, T. Chem. Soc. Rev. 1997, 26, 345. (f) Suzuki, A. Pure Appl. Chem. 1994, 66, 213.

(2) (a) Ishihara, K.; Yamamoto, H. Eur. J. Org. Chem. 1999, 527. (b) Ishihara, K.; Kurihara, H.; Yamamoto, H. J. Org. Chem. 1997, 62, 5664. (c) Ishihara, K.; Kurihara, H.; Yamamoto, H. Synlett 1997, 597. interactions, being able to behave as a Lewis acid or a Lewis base, as a Brønsted acid, and as a hydrogen-bond donor or acceptor.

This is clearly shown in the monomer-trimer equilibrium. We have recently ascertained that in the solid state $\mathbf{1}$ exists as a self-associated trimeric species $\mathbf{1}_{\mathbf{t}}$ (Chart $\left.\mathbf{1}\right)$, which in toluene solution dissociates to give the $\left(\mathrm{C}_{6} \mathrm{~F}_{5}\right)_{2} \mathrm{BOH}$ monomer $\mathbf{1}_{\mathbf{m}}$ (hereafter $\left.\mathrm{Ar}_{2} \mathrm{BOH}, \mathrm{Ar}=\mathrm{C}_{6} \mathrm{~F}_{5}\right){ }^{4}$ At variance, in dichlo-

(3) Recent patents dealing with synthesis or uses of 1: (a) Kratzer, R. (Basell Polyolefins) Patent WO 04041871, 2004. (b) Kratzer, R. (Basell Polyolefins) Patent WO 04007570, 2004. (c) Kratzer, R.; Fraaije, V. (Basell Polyolefins) Patent WO 04007569, 2004. (d) Takei, K.; Mizuta, K.; Aoki M.; Takebe, K. (Nippon Shokubai Co.) Patent JP 2004265785, 2004. (e) Ikeno, I.; Mitsui, H.; Iida, T.; Moriguchi, T. (Nippon Shokubai Co.) Patent WO 0248156, 2002. (f) Ikeno, I.; Mitsui, H.; Iida, T.; Moriguchi, T. (Nippon Shokubai Co.) Patent WO 0244185, 2002. (g) Schottek, J.; Fritze, C. (Targor) Patent DE 10009714, 2001. (h) Kratzer, R. (Basell Polyolefins) Patent DE 10059717, 2001. (i) Kratzer, R.; Fritze, C.; Schottek, J. (Targor) Patent DE 19962814, 2001. (j) Frances, J. M.; Deforth, T. (Rhodia Chimie) Patent WO 0130903, 2001. (k) Schottek, J.; Fritze, C.; Bohnen, H.; Becker, P. (Targor) WO 0020466, 2000. (1) Bohnen, H.; Hahn, U. (Aventis R\&T GMBH) Patent DE 19843055, 2000. (m) Bohnen, H. (Hoechst A.-G.) Patent DE 19733017, 1999.

(4) Beringhelli, T.; D’Alfonso, G.; Donghi, D.; Maggioni, D.; Mercandelli, P.; Sironi, A. Organometallics 2003, 22, 1588.

(5) Beringhelli, T.; D’Alfonso, G.; Donghi, D.; Maggioni, D.; Mercandelli, P.; Sironi, A. Organometallics 2004, 23, 5493.

(6) Britovsek, G, J, P.; Ugolotti, J.; Hunt, P.; White, A, J. P. Chem. Commun. 2006, 1295. 

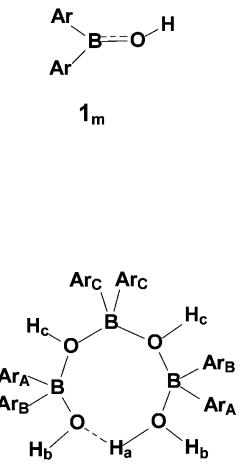

3

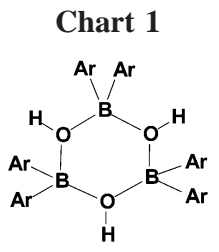

$1_{t}$

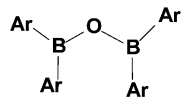

4
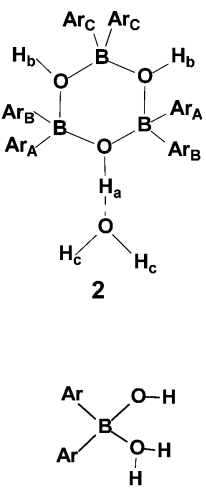

romethane solution sizable amounts of the trimeric form of $\mathrm{Ar}_{2}-$ $\mathrm{BOH}$ have been detected, in equilibrium with the dominant monomeric form. ${ }^{5}$ The trimeric form is unique, in that no other $\mathrm{B}_{3} \mathrm{O}_{3}$ cycle is known containing tetravalent boron atoms only.

$$
3 \mathrm{Ar}_{2} \mathrm{BOH} \rightleftarrows\left[\mathrm{Ar}_{2} \mathrm{BOH}\right]_{3}
$$

On decreasing the temperature, the equilibrium shifts to the right, but its attainment is very slow. This can be ascribed to intramolecular oxygen-to-boron $\pi$-donation, which imparts a partial double-bond character to the $\mathrm{B}-\mathrm{O}$ interaction ${ }^{4}$ and reduces both the nucleophilicity of the oxygen atom and the Lewis acidity of boron.

The presence of water strongly affects both the kinetics and the thermodynamics of this equilibrium. ${ }^{5}$ Semiempirical computations have depicted a trimerization pathway with a lower kinetic barrier in the presence of water than under anhydrous conditions and have also confirmed the stabilization of the trimeric form in the presence of water, due to the formation of a stable hydrogen-bonded adduct ( 2 in Chart 1 ), whose properties are still under investigation. An isomer of $\mathbf{2}$ was detected, ${ }^{5}$ namely, the adduct $\mathbf{3}$ of Chart 1 , containing a water molecule so strongly stabilized that it drives the partial spontaneous dehydration of $\mathbf{1}$ to its anhydride $\mathrm{Ar}_{2} \mathrm{BOBAr}_{2}, \mathbf{4}$ (Chart 1), as shown in the bottom trace of Figure 1.

The peculiar role of water in the association equilibria of $\mathbf{1}$ results from the multiple roles, complementary to those of $\mathbf{1}$, that water is able to play, as Lewis base and as hydrogen-bond donor and acceptor. In particular, its kinetic and thermodynamic effects depend on its nucleophilicity, which allows the formation of adducts $\mathbf{2}$ and $\mathbf{5}$ of Chart 1. Other Lewis bases might therefore be as effective. Here we have investigated the interaction of $\mathbf{1}$ with tetrahydrofuran (THF), i.e., with a very simple organic molecule that can act as a Lewis base and hydrogen-bond acceptor only. In particular, for THF the parameter $\beta_{2}$, which measures the H-bond basicity, ${ }^{7}$ is even higher than for water (0.51 vs 0.38$)$.

The capability of THF, as a Lewis base, to stabilize the trimeric form has been confirmed and found to be even stronger than expected. The interaction of $\mathbf{1}_{\mathbf{m}}$ with THF has been shown to occur via a $\mathrm{H}$-bond, further supporting its poor Lewis acidity. The unexpected occurrence of ionization equilibria has been discovered.

\section{Results and Discussion}

To study the reactivity between $\mathbf{1}$ and THF, we have used the same approach used to investigate the association equilibria

(7) Abraham, M. H., Grellier P. L., Prior D. V., Morris J. J., Taylor, P. J. J. Chem. Soc., Perkin Trans. 2 1990, 521.
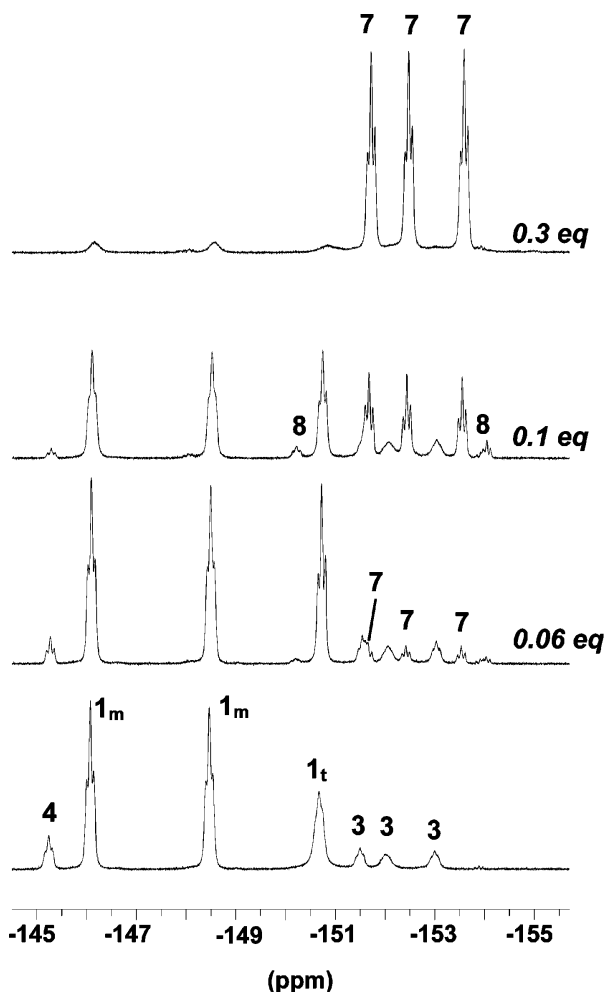

Figure 1. ${ }^{19} \mathrm{~F}$ NMR monitoring (para region) of a titration of a $\mathrm{CD}_{2} \mathrm{Cl}_{2}$ solution of 1 with $\mathrm{THF}$, up to 0.33 equiv, at $183 \mathrm{~K}$. The bottom trace, corresponding to the solution before THF addition, shows the mixture of $\mathbf{1}_{\mathbf{m}}, \mathbf{1}_{\mathbf{t}}, \mathbf{3}$, and $\mathbf{4}$ discussed in the Introduction.

involving water, ${ }^{5}$ i.e., variable-temperature titrations of $\mathbf{1}$ with the nucleophile, performed directly into NMR tubes and monitored by ${ }^{1} \mathrm{H}$ and ${ }^{19} \mathrm{~F}$ NMR.

Interaction between $\mathrm{Ar}_{2} \mathrm{BOH}$ (1) and $\mathrm{THF}$ at $283 \mathrm{~K}$. At the very beginning of the titration (up to ca. 0.3 equiv) THF interacted preferentially with $\mathbf{1}_{\mathbf{t}}$, as clearly revealed by the larger shift of the ${ }^{19} \mathrm{~F}$ signals of $\mathbf{1}_{\mathbf{t}}$ with respect to those of $\mathbf{1}_{\mathbf{m}}$ (Figures 2 and $3 \mathrm{a})$. The formation of the $\mathbf{1}_{\mathbf{t}} \cdot \mathrm{THF}$ adduct shifted equilibrium 1 toward the trimeric form (Figure $3 \mathrm{~b}) .{ }^{8}$ However, in the successive titration steps THF interacted with $\mathbf{1}_{\mathbf{m}}$ also (Figures 2, 3a, and S1), and this drove back equilibrium 1, resulting in the increase of the relative amount of the monomeric species (Figure $3 b$ ).

These findings are similar to those observed in the analogous titration with water. However, an unexpected difference was revealed by the ${ }^{11} \mathrm{~B}$ NMR monitoring, ${ }^{9}$ which showed that even in the presence of 3 equiv of THF the most intense signal was in the region of tricoordinated boron (ca. $40 \mathrm{ppm}$ ). With water, on the contrary, the ${ }^{11} \mathrm{~B}$ signal of the monomer shifted from the region of tri- to that of tetracoordination as soon as water uptake by $\mathbf{1}_{\mathbf{m}}$ became significant, eventually resulting in the disappearance of tricoordinated boron.

(8) These findings were supported also by the ${ }^{1} \mathrm{H}$ NMR spectra (shown in Figure S1 of the Supporting Information).

(9) This spectroscopy allows to discriminate between tri- and tetracoordinated boron species: (a) Kidd, R. J. In NMR of Newly Accessible Nuclei Laszlo, P., Ed.; Academic Press: New York, 1983; Vol. 2; Chapter 3. See also for instance: (b) Dagorne, S.; Guzei, I. A.; Coles, M. P.; Jordan, R. F. J. Am. Chem. Soc. 2000, 122, 274. (c) Fraenk, W.; Klapötke, T. M.; Krumm B.; Mayer, P. Chem. Commun. 2000, 667. (d) Kehr, G.; Fröhlich, R.; Wibbeling, B.; Erker, G. Chem.-Eur. J. 2000, 6, 258. (e) Jacobsen, H.; Berke, H.; Döring, S.; Kehr, G.; Erker, G.; Fröhlich, R.; Meyer, O. Organometallics 1999, 18, 1724. (f) Vagedes, D.; Fröhlich, R.; Erker, G. Angew. Chem., Int. Ed. 1999, 38, 3362. (g) Parks, D. J.; Piers, W. E.; Parvez, M.; Atencio, R.; Zaworotko, M. J. Organometallics 1998, 17, 1369. (h) Parks, D. J.; Piers, W. E.; Yap, G. P. A. Organometallics 1998, 17, 5492. (i) Sun, Y.; Piers, W. E.; Rettig, J. R. Organometallics 1996, 15, 4110. 


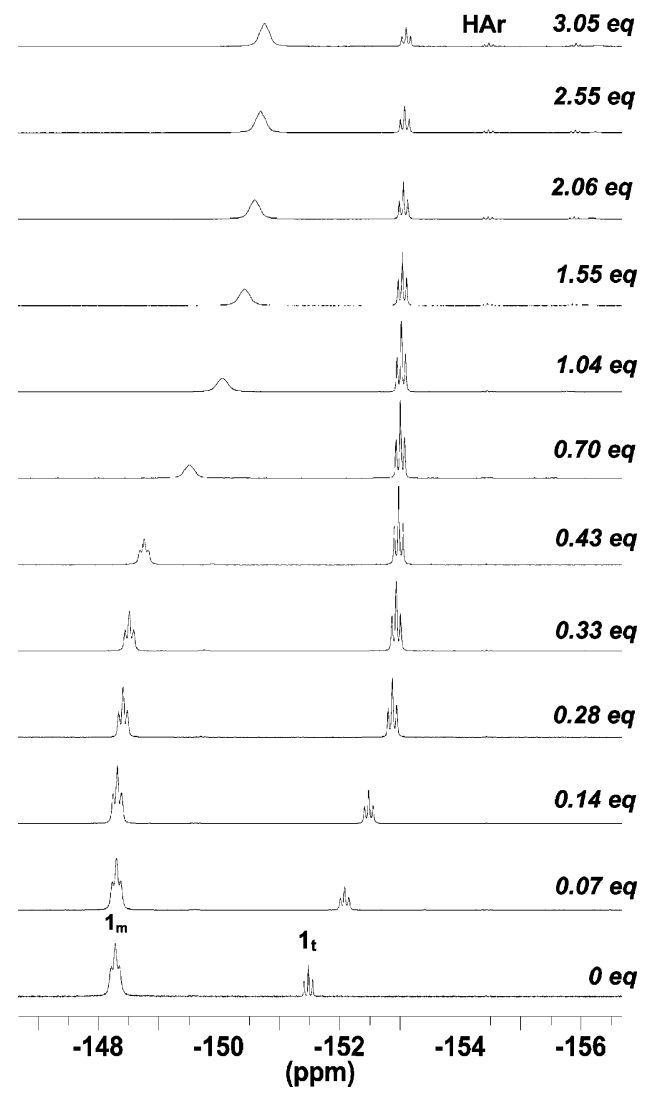

Figure 2. Para region of ${ }^{19} \mathrm{~F}$ NMR spectra of $\mathbf{1}$ treated with increasing amounts of THF $\left(\mathrm{CD}_{2} \mathrm{Cl}_{2}, 283 \mathrm{~K}\right)$. At this temperature $\mathbf{1}_{m}$ and $\mathbf{1}_{t}$ are in fast exchange with their respective adducts with $\mathrm{THF}$, so that molar fraction weighted averaged resonances are observed. The resonance marked with HAr is due to pentafluorobenzene.

Therefore the $\mathbf{1}_{\mathbf{m}}-$ THF interaction occurs mainly through a hydrogen bond, to give the adduct $\mathbf{6} \mathbf{b}$ of Chart 2, rather than the Lewis acid-base complex $\mathbf{6 a}$ of the same chart.

This finds further support in a PM3 calculation (see Experimental Section) of the relative stability of the two complexes. Indeed, we found that, in the case of THF, the H-bonded complex is more stable than the acid-base complex by $12 \mathrm{kcal}$ $\mathrm{mol}^{-1}$, while in the case of water the opposite holds, with a preference for the acid-base complex by $6 \mathrm{kcal} \mathrm{mol}^{-1}$. This preference can be attributed to the stronger H-bond basicity of THF with respect to water. Moreover, as can be seen by comparing the two optimized structures of the acid-base adducts $\mathbf{5}$ and $\mathbf{6 a}$ shown in Figure S2, the coordination of water to a borinic acid molecule is strengthened by the formation of an intramolecular interaction between one hydrogen atom of water and one of the ortho fluorine atoms of a perfluorophenyl ring, whereas the coordination of THF, lacking acidic hydrogen atoms, results in a crowded ligand arrangement around the boron atom, since the interaction of the incoming THF molecule with the bulky perfluorophenyl rings can be repulsive only.

Titration at $183 \mathrm{~K}$ up to 0.33 equiv of THF: Quantitative Formation of the Adduct $\left[\mathrm{Ar}_{2} \mathrm{BOH}\right]_{3} \cdot \mathrm{OC}_{4} \mathrm{H}_{8}$ (7). Lowtemperature $(183 \mathrm{~K})$ titrations showed the progressive formation, complete at 0.33 equiv (Figure 1), of the hydrogen-bonded adduct between $\mathbf{1}_{\mathbf{t}}$ and one molecule of THF ( $\mathbf{7}$ in Chart 2). The minor species $\mathbf{8}$ that appeared at the initial stages of the titration has been characterized as the adduct between borinic anhydride 4 and THF, shown in Chart 2 (see Supporting Information).
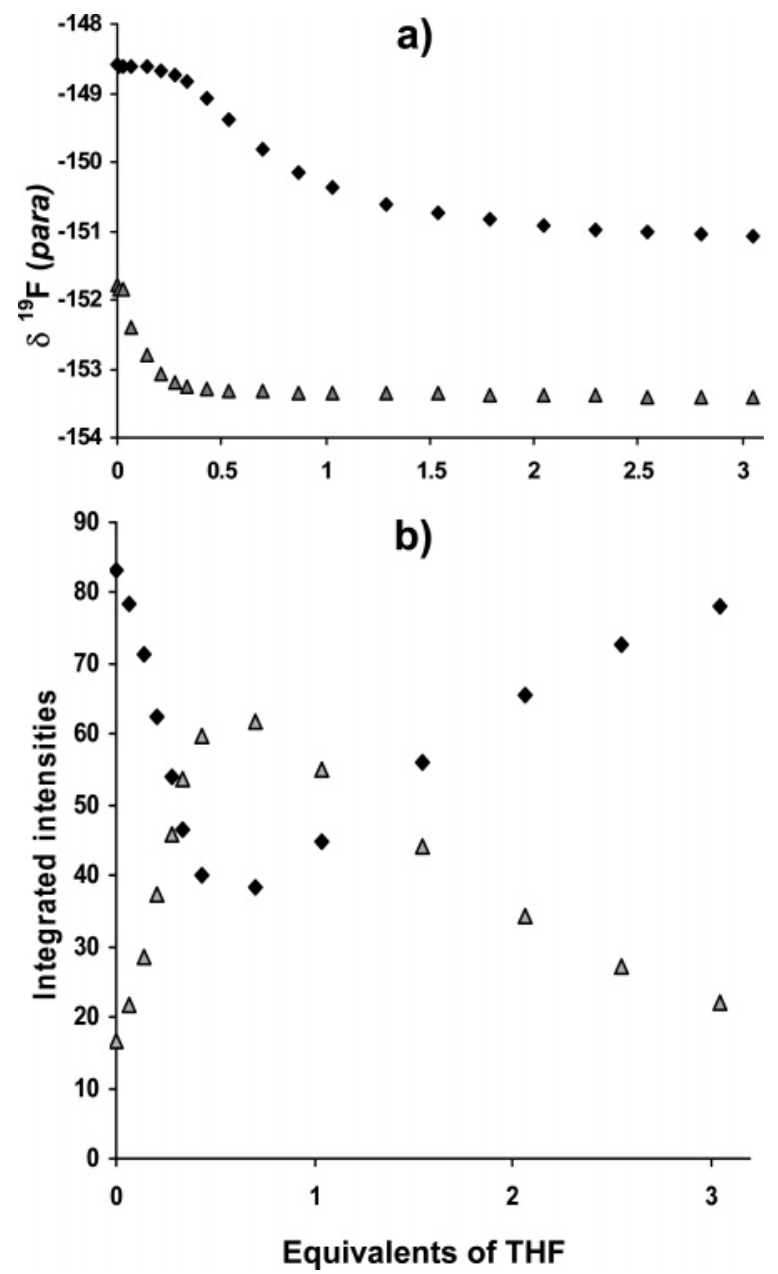

Figure 3. (a) Variation of the chemical shifts of the ${ }^{19} \mathrm{~F}$ para resonances of the monomeric ( $\downarrow$, averaged signals for $\mathbf{1}_{\mathbf{m}}$ and $\mathbf{6}$ ) and of the trimeric species ( $\boldsymbol{\Lambda}$, averaged signals for $\mathbf{1}_{\mathbf{t}}$ and $\left.\mathbf{7}\right)$ during the titration of 1 with THF, at 283 K. (b) Simultaneous variation of the corresponding integrated intensities (their overall intensity being set to 100).

\section{Chart 2}

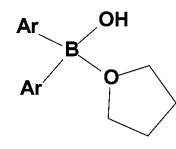

$6 \mathbf{a}$

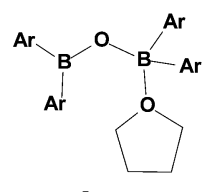

8

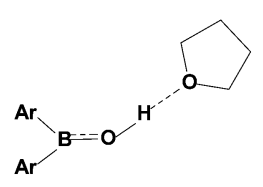

$6 b$

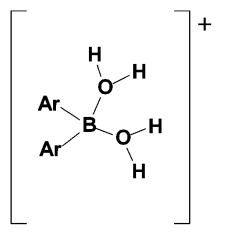

9

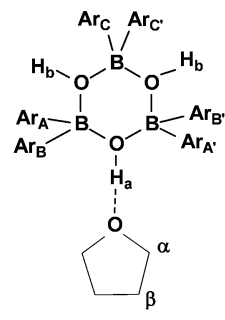

7

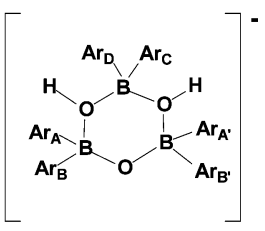

10
The adduct 7 exhibits $15{ }^{19} \mathrm{~F}$ signals (Figure S3, Table 1) and two $\mathrm{OH}$ resonances (ratio 1:2, Figure S4). The one at lower field $(\delta 14.5)$ is due to $\mathrm{H}_{\mathrm{a}}$, hydrogen-bonded to THF.

$\left[{ }^{19} \mathrm{~F}-{ }^{1} \mathrm{H}\right]$ HOESY, $\left[{ }^{19} \mathrm{~F}-{ }^{1} \mathrm{H}\right] \mathrm{COSY}$, and ${ }^{19} \mathrm{~F}$ COSY experiments (see Figures S5-S7 and Table S1 in the Supporting Information) led to a solution structure of $\mathbf{7}$ that is consistent 
Table 1. ${ }^{1} \mathrm{H}$ and ${ }^{19} \mathrm{~F}$ Chemical Shifts $\left(183 \mathrm{~K}, \mathrm{CD}_{2} \mathrm{Cl}_{2}\right)$ of the Novel Species Described in this Work, Labeled as Indicated in the Corresponding Charts

\begin{tabular}{|c|c|c|c|c|}
\hline \multirow[b]{2}{*}{ compound } & \multirow[b]{2}{*}{${ }^{1} \mathrm{H}(\mathrm{ppm})$} & \multicolumn{3}{|c|}{${ }^{19} \mathrm{~F}(\mathrm{ppm})$} \\
\hline & & ortho & para & meta \\
\hline 7 & $\begin{array}{c}14.41\left(\mathrm{~s}, \mathrm{H}_{\mathrm{a}}\right) \\
8.45\left(\mathrm{t}, 2 \mathrm{H}_{\mathrm{b}}\right) \\
3.65\left(\mathrm{~s}, 2 \mathrm{H}_{\alpha}\right) \\
3.03\left(\mathrm{~s}, 2 \mathrm{H}_{\alpha}\right) \\
1.78\left(\mathrm{~m}, 4 \mathrm{H}_{\beta}\right)\end{array}$ & $\begin{array}{l}-132.26(\mathrm{~A} 2),-141.17(\mathrm{~A} 6), \\
-132.85(\mathrm{~B} 2),-140.42(\mathrm{~B} 6), \\
-135.86(\mathrm{C} 2),-141.92(\mathrm{C} 6)\end{array}$ & $\begin{array}{l}-151.71(\mathrm{~A} 4) \\
-153.58(\mathrm{~B} 4) \\
-152.46(\mathrm{C} 4)\end{array}$ & $\begin{array}{l}-160.66(\mathrm{~A} 5),-161.11(\mathrm{~A} 3) \\
-161.29(\mathrm{~B} 5),-163.85(\mathrm{~B} 3) \\
-160.93(\mathrm{C} 3),-162.27(\mathrm{C} 5)\end{array}$ \\
\hline 8 & $\begin{array}{l}4.30\left(\mathrm{~m}, 4 \mathrm{H}_{\alpha}\right) \\
2.13\left(\mathrm{~m}, 4 \mathrm{H}_{\beta}\right)\end{array}$ & $\begin{array}{l}-132.97 \\
-133.73\end{array}$ & $\begin{array}{l}-150.06 \\
-153.90\end{array}$ & $\begin{array}{l}-161.78 \\
-162.78\end{array}$ \\
\hline 9 & $13.37(\mathrm{~s}, 4 \mathrm{H})$ & -136.17 & -153.23 & -161.95 \\
\hline $10^{a}$ & $8.88(\mathrm{~s}, 2 \mathrm{H})$ & $\begin{array}{l}-134.90(\mathrm{~A} 6),-140.04(\mathrm{~A} 2) \\
-132.40,-133.80-135.90 \\
-142.20\end{array}$ & $\begin{array}{l}-160.78(\mathrm{~A} 4), \\
-159.80(\mathrm{~B} 4) \\
-155.59(\mathrm{C} 4) \\
-159.53(\mathrm{D} 4)\end{array}$ & $\begin{array}{l}-165.54(\mathrm{~A} 3, \mathrm{~A} 5) \\
-165.05(\mathrm{~B} 3) \\
-163.20(\mathrm{C} 3, \mathrm{C} 5) \\
-166.73(\mathrm{~B} 5, \mathrm{D} 3, \mathrm{D} 5)\end{array}$ \\
\hline
\end{tabular}

${ }^{a}$ The incomplete assignment of the ortho signals is due to accidental overlap and broadening arising from ring dynamics. The assignments of the para and meta resonances to $C$ or $D$ rings is arbitrary.
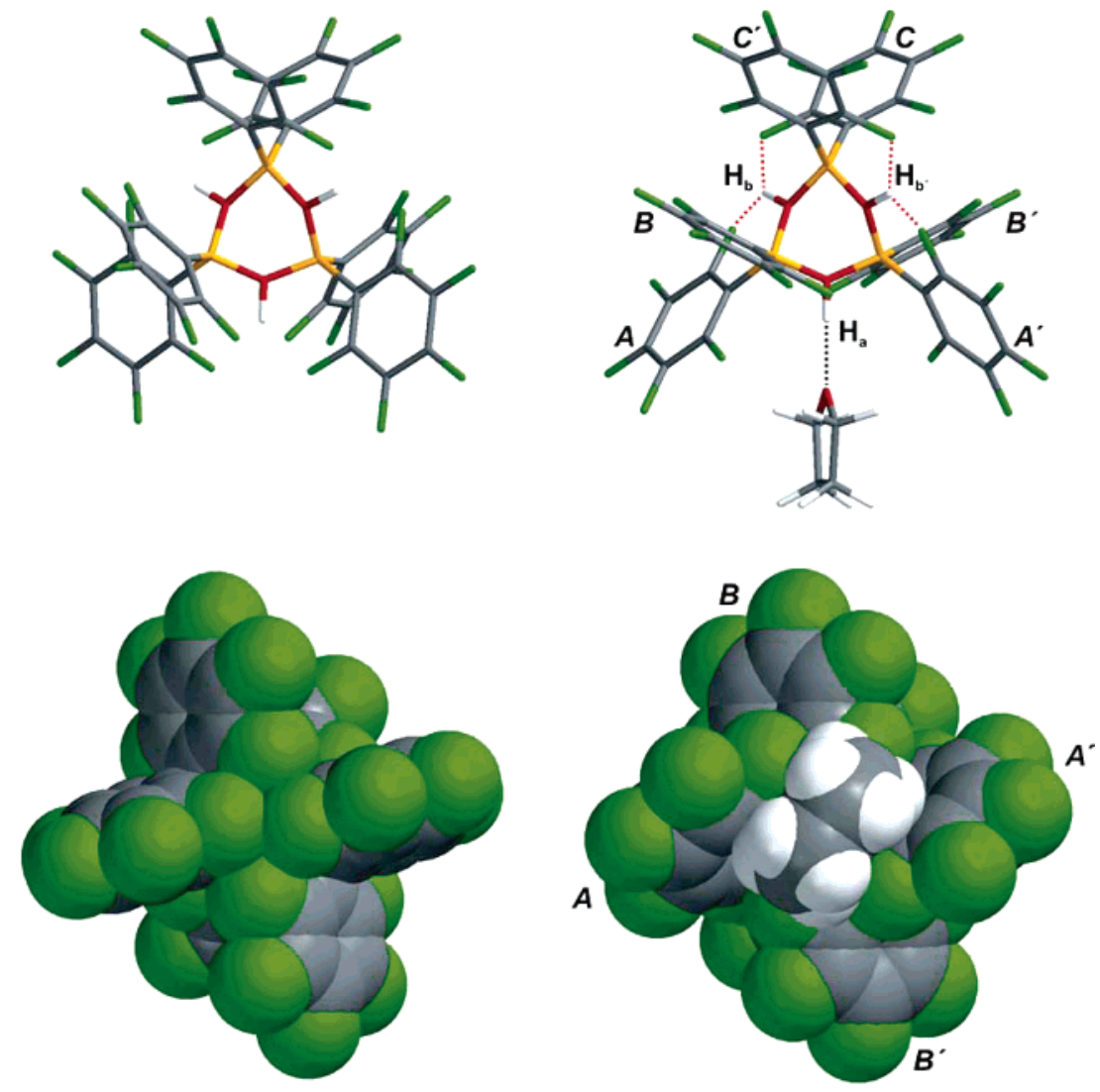

1 ,

7

Figure 4. Stick and space-filling models (PM3 $C_{2}$-optimized geometries) for the trimeric borinic acid $\mathbf{1}_{\mathbf{t}}$ and its adduct with THF, 7.

with the $C_{2}$ symmetric optimized geometry depicted in Figure 4. ${ }^{10}$ Short intramolecular $\mathrm{H} \cdots \mathrm{F}$ contacts are present between hydrogen atom $\mathrm{H}_{\mathrm{b}}$ and two ortho fluoro substituents on rings $A$ and $C$ (1.79 and $1.82 \AA$ with $A 6$ and $C 6$, respectively), in accordance with the observed strong scalar and dipolar coupling between these nuclei, resulting in particular in an $\mathrm{AB}$ system in the ${ }^{19} \mathrm{~F}$ spectrum (Figures $\mathrm{S} 3$ and S4). Similar short $\mathrm{H} \cdots \mathrm{F}$ contacts (1.83 and $1.82 \AA)$ are present in the optimized geometry

(10) The optimized structure of 7 only marginally deviates from an idealized $C_{2}$ symmetry, because of the position of the THF molecule with respect to the pseudo-2-fold axis. For the sake of clarity a symmetric $C_{2}$ structure, lying $0.1 \mathrm{kcal} \mathrm{mol}^{-1}$ above the minimum and corresponding to a first-order saddle point, is reported in Figure 4. of the parent trimeric acid $\mathbf{1}_{\mathbf{t}}$, shown in Figure 4. However, the highly fluxional behavior of $\mathbf{1}_{\mathbf{t}}$ hampers the direct observation of the dipolar or scalar couplings associated with these contacts. ${ }^{11-13}$

The insertion of the THF molecule in the pocket between the aromatic rings brings its protons close to the ortho fluorine atoms of rings $A$ and $B$, as clearly shown in the $\left[{ }^{19} \mathrm{~F}-{ }^{1} \mathrm{H}\right]$ HOESY map reported in Figure S5 and confirmed by PM3

(11) Also the strong coupling between the two fluorine atoms $A 6$ and C6 found in 7 is attributable to their proximity ${ }^{12}$ (2.48 A, much shorter than that measured in the crystals of $\mathbf{1}_{\mathbf{t}}, 2.91 \AA$ ) and is not to be thought as mediated by the hydrogen atom, as is the case of $F \mathrm{HF}$ scalar coupling observed in the anions $(\mathrm{HF})_{n} \mathrm{~F}^{-} .13$ 


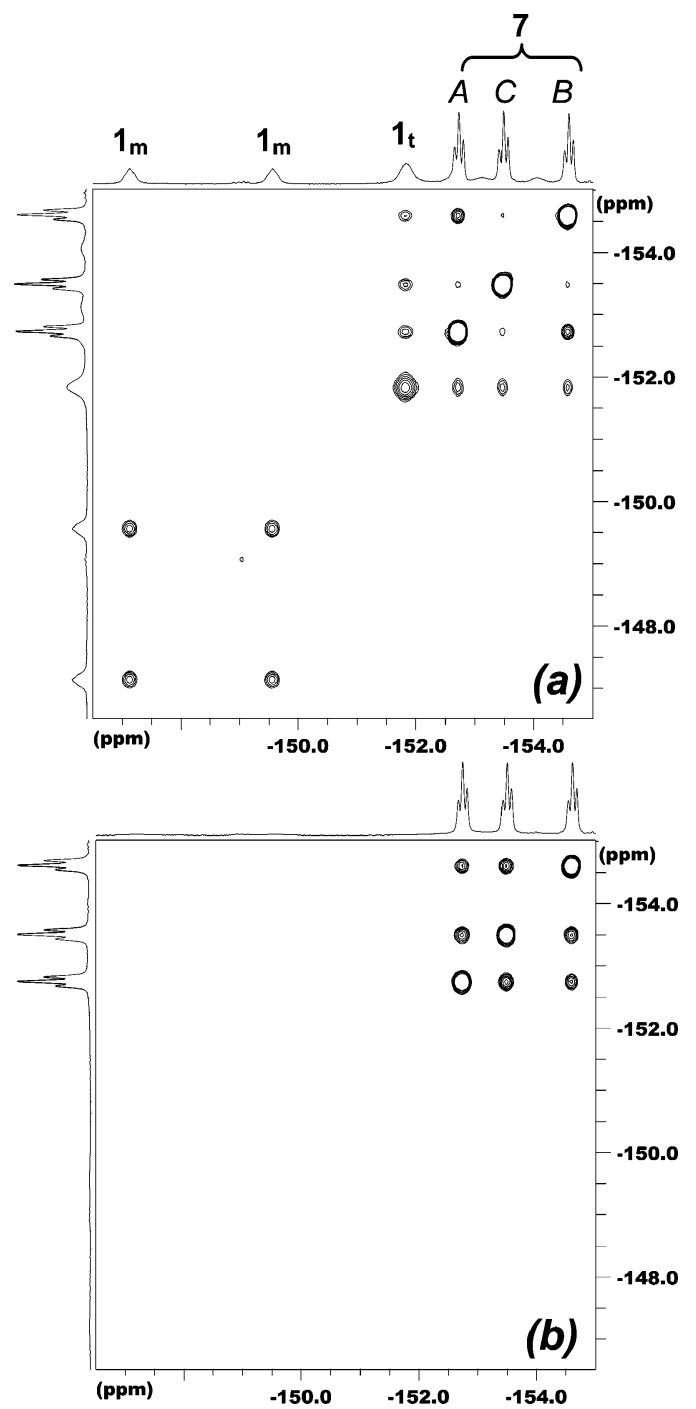

Figure 5. Para region of a $\left[{ }^{19} \mathrm{~F}-{ }^{19} \mathrm{~F}\right]$ EXSY experiment performed on a solution of 1 treated with (a) 0.18 and (b) 0.33 equiv of THF $\left(183 \mathrm{~K}, \mathrm{CD}_{2} \mathrm{Cl}_{2}, \tau_{\mathrm{m}}=0.15 \mathrm{~s}\right)$.

calculations. As can be seen comparing the space-filling models of $\mathbf{1}_{\mathbf{t}}$ and $\mathbf{7}$ (Figure 4), the hydrogen-bonding of a THF molecule determines major deformations in the molecular geometry of the borinic acid trimer. In particular, the hydrogen atom $\mathrm{H}_{\mathrm{a}}$, which in $\mathbf{1}_{\mathbf{t}}$ is completely screened by the perfluorophenyl rings, in 7 becomes accessible to the THF molecule by opening a pocket between the phenyl groups labeled $A$ and $A^{\prime}$ in Figure 4. This is easily possible on one of the three $\mathrm{B}-\mathrm{O}-\mathrm{B}$ edges only, since the conformation assumed by the fluorinated rings adjacent to the edge occupied by a H-bonded THF molecule leads to a more stiff conformation of the molecule, associated with a limited conformational freedom of the other aryl groups.

The adduct $\mathbf{7}$ exchanged with $\mathbf{1}_{\mathbf{t}}$, according to equilibrium 2 , as shown by 2D EXSY experiments (Figure 5a). The rate constants varied in the titration course: in particular, the values of $k_{7 \rightarrow 1 \mathrm{t}}$ increased roughly linearly with respect to the concentra-

(12) (a) Mallory, F. B.; Mallory, C. W.; Butler, K. E.; Lewis, M. B.; Qian Xia, A.; Luzik, E. D., Jr.; Fredenburgh, L. E.; Ramanjulu, M. M.; Van, Q. N.; Francl, M. M.; Freed, D. A.; Wray, C. C.; Hann. C.; NerzStormes, M.; Carrol, P. J.; Chirlian, L. E. J. Am. Chem. Soc. 2000, 122, 4108. (b) Peralta, J. E.; Barone, V.; Contreras, R. H.; Zaccari, D. G.; Snyder, J. P. J. Am. Chem. Soc. 2001, 123, 9162.

(13) Shenderovich, I. G.; Limbach, H-H.; Smirnov, S. N.; Tolstoy, P. M.; Denisov, G. S.; Golu bev, N. S. Phys. Chem. Chem. Phys. 2002, 4 5488 .

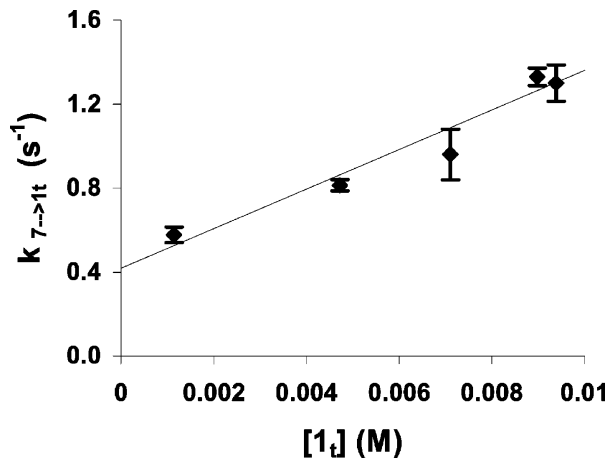

Figure 6. Dependence of the rate constant $k_{7 \rightarrow 1 \mathrm{t}}$ on the concentration of $\mathbf{1}_{\mathbf{t}}$ (estimated from the integrated intensities of the ${ }^{19} \mathrm{~F}$ signals) at $183 \mathrm{~K}$. The plotted values are averages and standard deviations of the three constants obtained from the volumes of the exchange cross-peaks of the three para signals of 7, in $2 \mathrm{D}\left[{ }^{19} \mathrm{~F}-{ }^{19} \mathrm{~F}\right]$ EXSY experiments. The intercept and the slope provide the contributions of a dissociative $\left(k_{1}=0.42(6) \mathrm{s}^{-1}\right)$ and a bimolecular $\left(k_{2}=94(11)\right.$ $\mathrm{M}^{-1} \mathrm{~s}^{-1}$ ) mechanism.

tion of $\mathbf{1}_{\mathbf{t}}$, with a nonzero intercept (Figure 6), suggesting that both dissociative and associative mechanisms operate in attaining equilibrium 2.

$$
\left(\mathrm{Ar}_{2} \mathrm{BOH}\right)_{3} \cdot \mathrm{THF} \leftrightarrows\left(\mathrm{Ar}_{2} \mathrm{BOH}\right)_{3}+\mathrm{THF}
$$

Titration at Low Temperature above 0.33 equiv of THF: Formation of Ionic Species. Above 0.33 equiv, at $183 \mathrm{~K}$, several new compounds were formed, although 7 remained the main solution species up to more than 2 equiv of THF. Conductivity measurements revealed the unexpected formation of ionic species. The conductivity value measured after the addition of 5 equiv of THF (at $198 \mathrm{~K}$ ) corresponded to ca. $25 \%$ of that measured in the same conditions for an equimolar solution of a true ionic compound $\left(\mathrm{NBu}_{4} \mathrm{PF}_{6}\right)$, showing that the ionization process involved a minor but significant part of the solution species.

A detailed analysis of the NMR spectra (see Supporting Information, Figures S8 and S9) allowed the identification of the main ionic species as the cation $\left[\mathrm{Ar}_{2} \mathrm{~B}\left(\mathrm{OH}_{2}\right)_{2}\right]^{+}(\mathbf{9})$ and the anion $\left[\mathrm{Ar}_{6} \mathrm{~B}_{3} \mathrm{O}_{3} \mathrm{H}_{2}\right]^{-}$, i.e., deprotonated $\mathbf{1}_{\mathbf{t}}(\mathbf{1 0}$ in Chart 2).

The cation 9 is stabilized by hydrogen bonds with THF, as indicated by the chemical shift of the protonic resonance of 9 $(\delta 13.4)^{14}$ and by the close proximity between THF and $\mathbf{9}$, revealed by homonuclear $\left[{ }^{1} \mathrm{H}-{ }^{1} \mathrm{H}\right]$ (Figure S10) and heteronuclear $\left[{ }^{19} \mathrm{~F}-{ }^{1} \mathrm{H}\right]$ 2D NOE correlation experiments.

The low-temperature ${ }^{19} \mathrm{~F}$ NMR data of $\mathbf{1 0}$ (four para resonances in the ratio $1: 1: 2: 2$ ) indicated that the anion has $C_{s}$ symmetry, at variance with $\mathbf{1}_{\mathbf{t}}$ or its adduct $\mathbf{7}$, which show a $C_{2}$ structure, in the solid state or in solution at low temperature, respectively. Geometry optimization for $\mathbf{1}_{\mathbf{t}}$ and $\mathbf{1 0}$ structures correctly reproduced these experimental findings, although for both these species both the $C_{s}$ and $C_{2}$ conformers were true minima on the potential energy surface, with energy differences less than $1 \mathrm{kcal} \mathrm{mol}^{-1}$.

Ions 9 and 10, even at low temperature in $\mathrm{CD}_{2} \mathrm{Cl}_{2}$, do not constitute a tight ion pair. Indeed, no correlation was detected (in homo- and heteronuclear NOE correlation experiments) between the ${ }^{1} \mathrm{H}$ or ${ }^{19} \mathrm{~F}$ signals of 9 and the ${ }^{19} \mathrm{~F}$ resonances of 10, ${ }^{15,16}$ while a $\left[{ }^{1} \mathrm{H}-{ }^{1} \mathrm{H}\right]$ correlation between 9 and THF was

(14) In the absence of H-bonding, the protons of B-bonded water molecules resonate at much higher fields: Beringhelli, T.; Maggioni, D.; D'Alfonso, G. Organometallics 2001, 20, 4927.

(15) In related systems, involving tight cation-borate interactions, interion $\left[{ }^{19} \mathrm{~F}-{ }^{1} \mathrm{H}\right]$ NOE correlations have been clearly detected. ${ }^{16}$ 
clearly recognizable (see above). Taking also into account the conductive properties of the solution, it should be concluded that the $\mathbf{9 . 1 0}$ ion pair is very labile. This is likely related to the high delocalization of the negative charge in the anion $\mathbf{1 0},{ }^{17,18}$ as well as to steric factors, preventing a very close $\mathrm{O}-\mathrm{H} \cdots \mathrm{O}$ interaction in the $\mathbf{9 . 1 0}$ pair, and to the high dielectric constant of $\mathrm{CH}_{2} \mathrm{Cl}_{2}$ at low temperature, ${ }^{19}$ which favors ion separation.

The fate of the ions at higher temperatures could not be clearly ascertained, because on increasing the temperature all the resonances broadened and decreased in intensity, leading eventually at $273 \mathrm{~K}$ to one protonic signal and only one set of ${ }^{19} \mathrm{~F}$ resonances. However, conductivity measurements at $273 \mathrm{~K}$ showed that ionic species are present even at higher temperatures, although in a smaller relative amount. ${ }^{20}$

The occurrence of ionization above 0.33 equiv of THF can be rationalized by the following considerations. The excess of THF causes a partial cleavage of the trimeric structure of 7 , because at this point THF can interact (by H-bonding) only with the small amount of $\mathbf{1}_{\mathbf{m}}$ in equilibrium with $\mathbf{7}$ (the binding of a second THF molecule to the trimer is unfavored for steric reasons, as discussed above). This drives to the left the monomer-trimer equilibrium 1 , affording the $\mathbf{1}_{\mathbf{m}} \cdot \mathrm{THF}$ adduct(s) 6 (according to the overall equilibrium 3 ).

$$
\left(\mathrm{Ar}_{2} \mathrm{BOH}\right)_{3} \cdot \mathrm{THF}+2 \mathrm{THF} \leftrightarrows 3 \mathrm{Ar}_{2} \mathrm{~B}(\mathrm{OH}) \cdot \mathrm{THF}
$$

From this point of view, the role of THF is similar to that previously observed for water, ${ }^{5}$ except for the different mode of preferred interaction with $\mathbf{1}_{\mathbf{m}}$ (H-bond for THF, coordination for water).

The traces of water present in solution can easily react with the $\mathbf{1}_{\mathbf{m}} \cdot$ THF adducts (eq 4), affording the tetracoordinated $\mathrm{Ar}_{2} \mathrm{~B}$ $(\mathrm{OH})\left(\mathrm{OH}_{2}\right)$ adduct $(\mathbf{5})$, stabilized by $\mathrm{H}$-bonding to THF.

$$
\mathrm{Ar}_{2} \mathrm{~B}(\mathrm{OH}) \cdot \mathrm{THF}+\mathrm{H}_{2} \mathrm{O} \leftrightarrows \mathrm{Ar}_{2} \mathrm{~B}(\mathrm{OH})\left(\mathrm{OH}_{2}\right)+\mathrm{THF}
$$

Water coordination increases the basicity of the oxygen atom of borinic acid, driving to the right equilibrium 5 .

$$
\begin{array}{r}
\left(\mathrm{Ar}_{2} \mathrm{BOH}\right)_{3} \cdot \mathrm{THF}+\mathrm{Ar}_{2} \mathrm{~B}(\mathrm{OH})\left(\mathrm{OH}_{2}\right) \leftrightarrows\left[\mathrm{Ar}_{6} \mathrm{~B}_{3} \mathrm{O}_{3} \mathrm{H}_{2}\right]^{-}+ \\
{\left[\mathrm{Ar}_{2} \mathrm{~B}\left(\mathrm{OH}_{2}\right)_{2}\right]^{+} \cdot \mathrm{THF}}
\end{array}
$$

The above proton transfer is likely mediated by the formation of the homoconjugate $[(\mathrm{THF}) \mathrm{H}(\mathrm{THF})]^{+}$pair, which drives to the right the ionization equilibrium 6 . Actually, in the absence of a THF excess, the adduct between $\mathbf{1}_{\mathbf{t}}$ and THF is in its neutral $\mathrm{BO}-\mathrm{H} \cdot \cdots \mathrm{THF}$ form 7 , as confirmed by the absence of significant conductivity up to 0.33 equiv of THF. The excess of THF would therefore act as a proton shuttle, according to eqs 6 and 7.

(16) Di Saverio, A.; Focante, F.; Camurati, I.; Resconi, L.; Beringhelli, T.; D’Alfonso, G.; Donghi, D.; Maggioni, D.; Mercandelli, P.; Sironi, A. Inorg. Chem. 2005, 44, 5030.

(17) Electrostatic potential maps computed for a series of perfluorophenyl borate anions showed a considerable reduction of the negative potential on the oxygen atom and on the whole accessible surface of the anion on increasing the number of perfluorophenyl rings. ${ }^{16}$

(18) Schott, D.; Pregosin, P. S.; Jacques, B.; Chavarot, M.; Rose-Munch, F.; Rose, E. Inorg. Chem. 2005, 44, 5941.

(19) Gründemann, S.; Ulrich, S.; Limbach, H. H.; Golubev, N. S.; Denisov, G. S.; Epstein, L. M.; Sabo-Etienne, S.; Chaudret, B. Inorg. Chem. 1999, 38,2550 .

(20) The conductivity at $273 \mathrm{~K}$, although higher, corresponded to only $11 \%$ of that of $\mathrm{NBu}_{4} \mathrm{PF}_{6}$ in the same conditions, indicating that the relative amount of ionized species decreases on increasing the temperature, likely due to the parallel significant decrease of the dielectric constant of $\mathrm{CD}_{2} \mathrm{Cl}_{2}$ (from 17 at $170 \mathrm{~K}$ to 9 at room temperature). ${ }^{19}$

$$
\begin{array}{r}
\left(\mathrm{Ar}_{2} \mathrm{BOH}\right)_{3} \cdot \mathrm{THF}+\mathrm{THF} \leftrightarrows\left[\mathrm{Ar}_{6} \mathrm{~B}_{3} \mathrm{O}_{3} \mathrm{H}_{2}\right]^{-}+ \\
{[(\mathrm{THF}) \mathrm{H}(\mathrm{THF})]^{+}}
\end{array}
$$

$$
\begin{aligned}
& {[(\mathrm{THF}) \mathrm{H}(\mathrm{THF})]^{+}+\mathrm{Ar}_{2} \mathrm{~B}(\mathrm{OH})\left(\mathrm{OH}_{2}\right) \leftrightarrows} \\
& \quad\left[\mathrm{Ar}_{2} \mathrm{~B}\left(\mathrm{OH}_{2}\right)_{2}\right]^{+} \cdot \mathrm{THF}+\mathrm{THF}
\end{aligned}
$$

Dynamics of 7. The rarity of six-membered $\mathrm{B}_{3} \mathrm{O}_{3}$ rings containing tetravalent boron only prompted us to investigate in detail the solution behavior of $\mathbf{7}$. Indeed in the case of $\mathbf{1}_{\mathbf{t}}$ (which has $C_{2}$ symmetry in the solid state) this study was prevented by its fast dynamics, which afforded an apparent $D_{3 h}$ symmetry even at the lowest temperatures. The low-temperature spectra of 7 , on the contrary, agree with the $C_{2}$ symmetry expected for this species (Figures S3 and S4). On increasing the temperature, the ${ }^{1} \mathrm{H}$ and ${ }^{19} \mathrm{~F}$ resonances of 7 broadened and coalesced (Figures 7 and 8), eventually affording one set of averaged ${ }^{19} \mathrm{~F}$ signals, as well as one averaged $\mathrm{BOH}$ resonance, indicative of an apparent $D_{3 h}$ symmetry. This implies the onset of at least three different dynamic processes: (i) the flopping of the cycle conformation, leading to equalization of the $A / B$ rings of Chart 2 ; (ii) the rotation of the aromatic rings around their $\mathrm{B}-\mathrm{C}$ bonds, equalizing the $2 / 6$ and $3 / 5$ positions within each ring; and then (iii) the exchange of $\mathrm{THF}$ among the three $\mathrm{OH}$ groups.

The details of the exchange processes were provided by 2D EXSY experiments, performed at $183 \mathrm{~K}$. Reliable rate constants could be evaluated from the cross-peak volumes ${ }^{21}$ between the para resonances only, since these did not show the accidental overlap observed in the meta region; neither were they affected by NOE contributions, as occurred for the ortho resonances. Due to these problems, the above ii exchanges could not be investigated.

The rate of the cycle flopping (exchange of rings $A$ and $B$ of Chart 2) remained substantially constant in the titration course $\left(k_{\mathrm{A} \rightarrow \mathrm{B}} 0.78-0.90 \mathrm{~s}^{-1}\right)$. On the contrary, the rate at which $C$ exchanged with both rings $A$ and $B$ increased with the amount of added THF (Figures $5 \mathrm{a}$ and $5 \mathrm{~b}$ ), ${ }^{22}$ showing that THF migration occurs by a bimolecular process. Upon addition of an excess of THF, the exchange became so fast to average the resonances of 7 , both in the ${ }^{1} \mathrm{H}$ and in the ${ }^{19} \mathrm{~F}$ spectra, even at $183 \mathrm{~K}$ (Figures S8 and S9).

The higher fluxionality of $\mathbf{1}_{\mathbf{t}}$ with respect to $\mathbf{7}$ might be ascribed to the increased rigidity imparted to the trimeric cyclic structure by the coordination of a THF molecule, as previously stated. However, a low-temperature structure of reduced symmetry ( $C_{s}$ in this case) has been observed for the trimeric anion $\mathbf{1 0}$ as well. This species can hardly be considered more rigid than $\mathbf{1}_{\mathbf{t}}$, because the lack of the $\mathrm{H} \cdots \mathrm{F}$ interactions involving one of the hydroxo groups is expected to promote phenyl ring mobility in $\mathbf{1 0}$.

To cast light on these differences, PM3 computations have been performed on $\mathbf{1}_{\mathbf{t}}, \mathbf{7}$, and $\mathbf{1 0}$. The computations showed that the flopping of the cycle conformation can take place in both the $C_{2}$ and the $C_{s}$ conformers of $\mathbf{7}$ and 10, leading to the exchange of the $A$ and $B$ rings and, for the $C_{s}$ anion, to the exchange of the rings bound to the boron atom lying on the

(21) Perrin, C. L.; Dwyer, T. J. Chem. Rev. 1990, 90, 935.

(22) At the beginning of the titration the $k$ values were too small to be measured, and successively they increased with THF concentration: $k_{\mathrm{C} \rightarrow \mathrm{A}}$ $=k_{\mathrm{C} \rightarrow \mathrm{B}}=0.13 \mathrm{~s}^{-1}$ ( 0.10 equiv), $0.23 \mathrm{~s}^{-1}$ ( 0.18 equiv), $1.26 \mathrm{~s}^{-1}$ ( 0.30 equiv), $1.70 \mathrm{~s}^{-1}(0.33$ equiv). It must be considered that when the amount of added THF is close to the stoichiometric ratio, the $A / B$ cross-peaks account not only for their direct exchange but also for their indirect exchange, through successive $A \rightarrow C$ and $C \rightarrow B$ steps, and therefore the $A / B$ exchange rate increases 


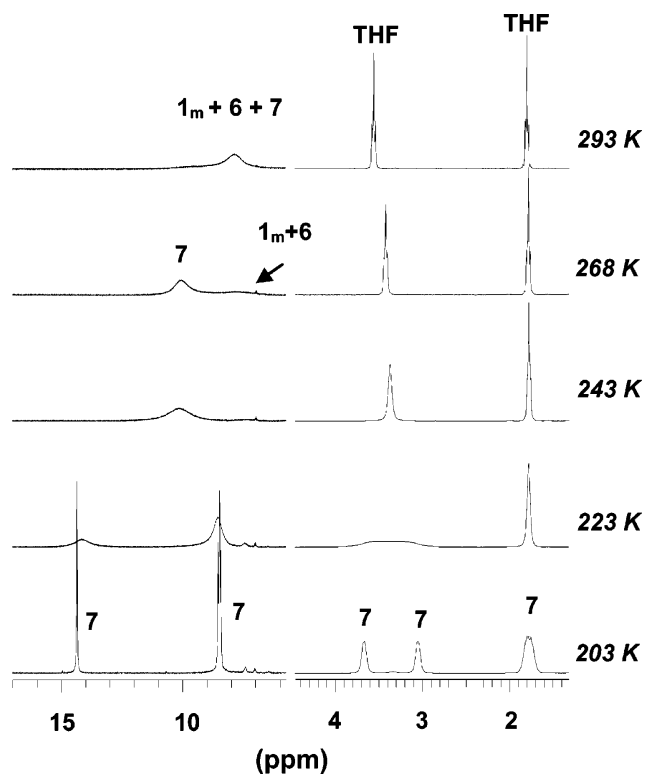

Figure 7. Variable-temperature ${ }^{1} \mathrm{H}$ NMR spectra of 7.

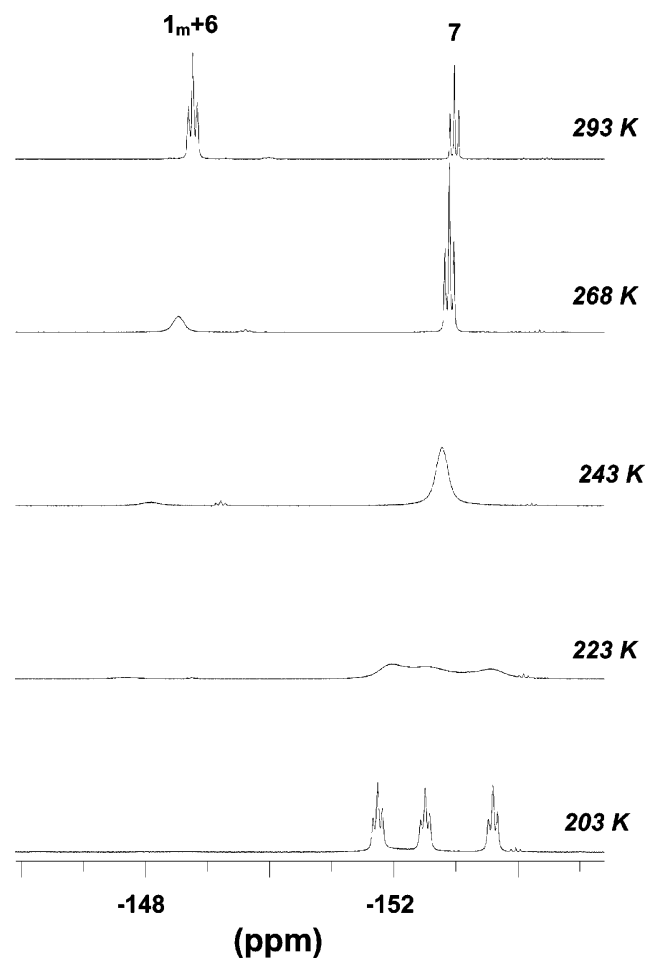

Figure 8. Variable-temperature ${ }^{19} \mathrm{~F}$ NMR spectra of 7 (para region)

symmetry plane of the molecule ( $C$ and $D$ in Chart 2). For 7 the $C_{s}$ conformer, lying $3 \mathrm{kcal} \mathrm{mol}^{-1}$ higher than the $C_{2}$ one, appears to be the transition structure of the process at study, whereas for $\mathbf{1 0}$ both structures are minima and the (asymmetric) transition structure connecting them lies at $2.4 \mathrm{kcal} \mathrm{mol}^{-1}$. This process of ring inversion, when associated with the rotation of the phenyl rings around their boron $-\mathrm{C}_{\mathrm{ipso}}$ bonds, leads to a dynamic $C_{2 v}$ symmetry for both species.

A similar interconversion between the $C_{2}$ and $C_{s}$ conformers can be computed for the parent trimeric acid $\mathbf{1}_{\mathbf{t}}$ as well, with an energy barrier $\left(2.6 \mathrm{kcal} \mathrm{mol}^{-1}\right)$ comparable to that computed for ring inversion in $\mathbf{7}$ and $\mathbf{1 0}$. However, for $\mathbf{1}_{\mathbf{t}}$ another different dynamic process can be envisaged, i.e., the pseudorotation of the six-membered $\mathrm{B}_{3} \mathrm{O}_{3}$ ring implying the exchange between the $C_{2}$ conformer depicted in Figure 4 and a $C_{s}$ conformer in
Scheme 1. Role of the Nucleophiles $\mathrm{OR}_{2}\left(\mathrm{H}_{2} \mathrm{O}\right.$ or THF) in the Oligomerization Equilibria of 1

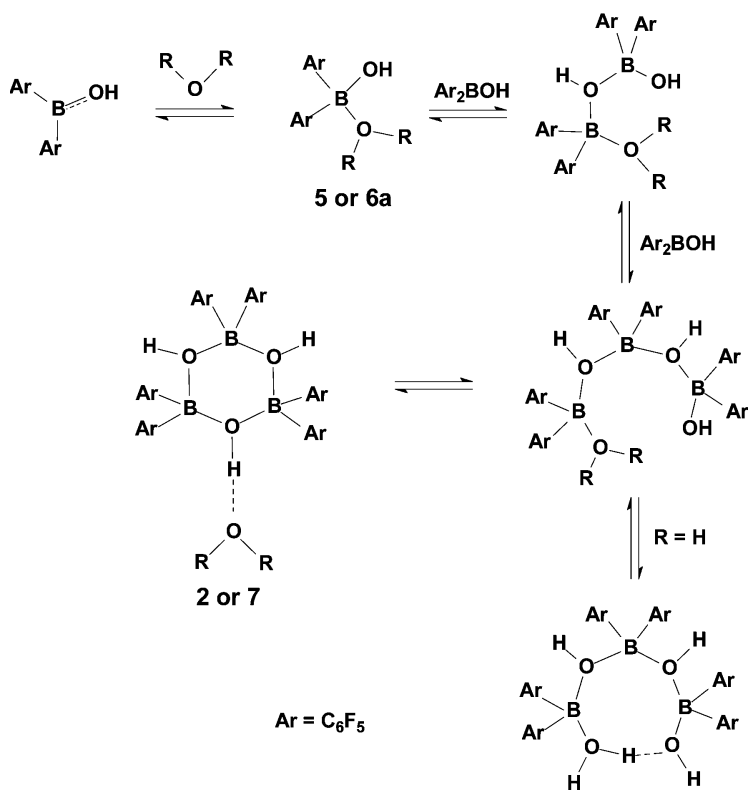

which $\mathrm{H}_{\mathrm{b}}$ (and not $\mathrm{H}_{\mathrm{a}}$ ) lies on the molecular symmetry plane. This process exchanges rings $C$ with both $A$ and $B$ and leads to a $D_{3 h}$ dynamic structure with an activation energy of less than $1 \mathrm{kcal} \mathrm{mol}^{-1}$. In the case of $\mathbf{7}$ and $\mathbf{1 0}$, this pseudorotation process is not allowed, unless it is accompanied by the (formal) transfer of a THF molecule (for 7) or a proton (for 10) from one point to the other of the molecule.

Thermal Stability of the Trimeric Cycle of 7. The variabletemperature spectra of Figure 8 revealed also the expected progressive fragmentation of the trimeric structure of 7 on increasing the temperature. Indeed at $T>240 \mathrm{~K}$ a novel set of ${ }^{19} \mathrm{~F}$ resonances appeared, at chemical shifts that can be confidently viewed as a molar fraction weighted average between those of $\mathbf{1}_{\mathbf{m}}$ and of the $\mathbf{1}_{\mathbf{m}} \cdot$ THF adduct(s) $\mathbf{6} .^{23}$

The ratio $R$ of the integrated intensities of the novel signals with respect to those of $\mathbf{7}$ strongly increased with the temperature ( $R=0.08$ at $243 \mathrm{~K}, 0.34$ at $268 \mathrm{~K}, 2.3$ at $293 \mathrm{~K}$ ), so that at room temperature one-third of borinic acid was present in the trimeric form. This confirms that the stabilization of the trimeric form upon $\mathrm{H}$-bonding with $\mathrm{THF}$ is effective even at room temperature. Indeed, in the absence of THF, the amount of $\mathbf{1}_{\mathbf{t}}$ at $298 \mathrm{~K}$ is negligible.

The fragmentation process was completely reversible, and on lowering back the temperature quantitative re-aggregation to the trimeric adduct 7 was observed.

\section{Conclusions}

The title compound in the solid state offers the first example of a trimeric structure based on only tetracoordinated boron atoms, ${ }^{4}$ and in dichloromethane solution it gives rise to an unprecedented monomer-trimer equilibrium. ${ }^{5}$ The study of the behavior of $\mathbf{1}$ in the presence of THF has now provided more insight into this trimerization equilibrium and into structure, dynamics, and stability of these unusual $\mathrm{B}_{3} \mathrm{O}_{3}$ rings.

(23) Moreover, the ${ }^{19} \mathrm{~F} T_{1}$ values of the novel signals, measured at 268 $\mathrm{K}$, were significantly longer than those of $\mathbf{7}$, in line with a smaller nuclearity: $1.18(3) \mathrm{s}$ and $1.40(8) \mathrm{s}$, for the novel ortho and para signals, vs $0.42(1) \mathrm{s}$ and $0.51(1) \mathrm{s}$ for the corresponding signals of 7 (in parentheses the uncertainties on the last digit). 
The addition of a Lewis base to a trivalent boron compound should be expected to lead to the formation of a covalent acidbase adduct, and the story should stop there. In the present case, on the contrary, this is only the beginning of a number of interlaced fast aggregations equilibria, which deeply modify the nature of the solution species.

Indeed, it is enough to add 0.33 equiv of THF, at a temperature as low as $183 \mathrm{~K}$, to instantaneously (and quantitatively) convert the monomer into the trimer (while in the absence of the nucleophile the attainment of the equilibrium required more than $10 \mathrm{~h}$ at $283 \mathrm{~K}){ }^{5}$ As previously shown by PM3 calculations in the case of $\mathrm{H}_{2} \mathrm{O},{ }^{5}$ the impressive effect of Lewis bases is attributable to the formation of adducts such as $\mathbf{5}$ or $\mathbf{6 a}$ (the latter present in small but kinetically significant concentration). The stronger nucleophilicity of the oxygen atom of $\mathbf{1}_{\mathbf{m}}$ in these adducts favors the formation of the di- and trinuclear oligomers of Scheme 1; then the displacement of the nucleophile by a $\mathrm{BO}(\mathrm{H})$ group leads to the formation of the trimeric cycle of $\mathbf{1}_{\mathbf{t}}$ stabilized by the exo-cyclic H-bond.

THF affects also the thermodynamics of the trimerization equilibrium 1, as shown by the observed increase of the relative amount of the trimer in the presence of THF: indeed the H-bond with the trimer (in 7) is stronger than that with the monomer (in 6b), in agreement with the higher effective electronegativity of an oxygen atom bound to two acidic boron centers. ${ }^{5}$

The crucial role played by the establishment of hydrogen bonds is a recurring feature in the reactivity of $\mathbf{1}$ : the propensity to act as a H-bond acceptor, together with the poor Lewis acidity of its B atom, explains the surprising finding that THF preferentially interacts with a trivalent boron derivative such as $\mathbf{1}_{\mathbf{m}}$ by $\mathrm{H}$-bonding (giving $\mathbf{6 b}$ ) rather then by formation of the acid-base adduct.

Another very unexpected feature revealed by this work is the occurrence of ionization equilibria involving the title compound in the presence of even a small excess of THF. Interestingly, in this process a proton is transferred from a trimeric to a monomeric form of borinic acid: more precisely the deprotonation of the acid $\mathbf{1}_{\mathbf{t}}$ is accompanied by protonation of the $\mathbf{1}_{\mathbf{m}} \cdot \mathrm{H}_{2} \mathrm{O}$ adduct $\mathbf{5}$. This shows that in suitable conditions (i.e., upon activation by coordination of a nucleophile) bis(pentafluorophenyl)borinic acid can exhibit Brønsted base properties, in addition to its more obvious properties as a Brønsted acid and Lewis acid and base.

In conclusion, this work shows that much care should be taken when one is working with this type of deceptively simple molecules, because the nature of the species present in solution can be very different from that expected.

\section{Experimental Section}

All the manipulations were performed under $\mathrm{N}_{2}$ using oven-dried Schlenk-type glassware. $\mathrm{CD}_{2} \mathrm{Cl}_{2}$ (C.I.L.) was dried on activated molecular sieves. THF was distilled from $\mathrm{Na} / \mathrm{Ph}_{2} \mathrm{CO}$. $\mathrm{B}\left(\mathrm{C}_{6} \mathrm{~F}_{5}\right)_{2} \mathrm{OH}$ was a gift from Basell Polyolefins. Its purity was checked by ${ }^{1} \mathrm{H}$ and ${ }^{19} \mathrm{~F}$ NMR and always resulted higher than $99 \%$. For some experiments, the samples were further sublimed (393 K, $10^{-5} \mathrm{mbar}$ ).

NMR spectra were acquired on a Bruker AVANCE DRX-300 spectrometer, equipped with $5 \mathrm{~mm}$ TBI or QNP probes, and on a Bruker AVANCE DRX-400 spectrometer, equipped with a $5 \mathrm{~mm}$ BBI probe. ${ }^{19} \mathrm{~F}$ NMR spectra were referenced to external $\mathrm{CFCl}_{3}$. The temperature was calibrated with a standard $\mathrm{CH}_{3} \mathrm{OH} / \mathrm{CD}_{3} \mathrm{OD}$ solution. ${ }^{24}$ Pentafluorotoluene $\left(\mathrm{C}_{6} \mathrm{~F}_{5} \mathrm{CH}_{3}, 1 \mu \mathrm{L}\right)$ was added to each sample, as an internal standard for both ${ }^{1} \mathrm{H}$ and ${ }^{19} \mathrm{~F}$ spectra.

(24) Van Geet, A. L. Anal. Chem. 1970, 42, 67.
Interaction between 1 and THF. A typical sample was prepared as follows. The appropriate amount of $\left(\mathrm{C}_{6} \mathrm{~F}_{5}\right)_{2} \mathrm{BOH}$ was weighted directly into the NMR tube and then dissolved in $\mathrm{CD}_{2} \mathrm{Cl}_{2}$, affording typically $0.10 \mathrm{M}$ solutions. THF was then added stepwise with a microsyringe. It has been checked that the results did not change upon performing THF addition at room temperature or at $193 \mathrm{~K}$. The spectra acquired at $193 \mathrm{~K}$ showed the progressive formation (up to 0.33 equiv of THF) of the adduct 7 , which exhibits two $\mathrm{OH}$ resonances ( $\delta 14.5$ and 8.45 , ratio $1: 2$, Figure $\mathrm{S} 4$ ) and $15^{19} \mathrm{~F}$ signals (six ortho and meta, three para, Figure S3). All the ${ }^{1} \mathrm{H}$ and ${ }^{19} \mathrm{~F}$ data are reported in Table $1 .\left[{ }^{19} \mathrm{~F}-{ }^{1} \mathrm{H}\right]$ HOESY, $\left[{ }^{19} \mathrm{~F}-{ }^{1} \mathrm{H}\right]$ COSY, and ${ }^{19} \mathrm{~F}$ COSY experiments (shown in Figures S5-S7 in the Supporting Information) as well as ${ }^{19} \mathrm{~F}$ NOESY experiments (not shown) allowed the assignments of the fluorine resonances reported in Table 1 and the determination of the $\mathrm{H}-\mathrm{F}$ and $\mathrm{F}-\mathrm{F}$ correlations reported in Table S1 of the Supporting Information. Such correlations are consistent with the optimized structure of $\mathbf{7}$ reported in Figure 4.

Another titration experiment (performed as above, by treating a $0.164 \mathrm{M} \mathrm{CD}_{2} \mathrm{Cl}_{2}$ solution of 1 with THF, up to 3 equiv) was monitored at $283 \mathrm{~K}$. In this case, besides ${ }^{1} \mathrm{H}$ and ${ }^{19} \mathrm{~F}$ spectra, also ${ }^{11} \mathrm{~B}$ data were acquired (quadrupolar broadening hampering the acquisition of these data in the titrations monitored at $183 \mathrm{~K}$ ).

Conductometric Measurements. A conductometric cell (AMEL 160 , cell constant $=0.90 \mathrm{~cm}$ ) was introduced under $\mathrm{N}_{2}$ in a Schlenklike vessel containing $3 \mathrm{~mL}$ of a $0.055 \mathrm{M}$ solution of $\mathbf{1}$ in $\mathrm{CH}_{2} \mathrm{Cl}_{2}$, in a thermostatic bath (at 193 or $273 \mathrm{~K}$, in two different experiments). The conductivity was measured in the presence of different amounts of THF, added under $\mathrm{N}_{2}$ atmosphere, up to 5 equiv. The following values of conductivity $\left(\mu \mathrm{S} \mathrm{cm}^{-1}\right)$ were measured (in parentheses the equivalents of added THF): $193 \mathrm{~K}$ : 0.29 (0), 0.46 (0.33), 4.07 (1), 12.4 (2), 17.1 (3), 18.6 (4), 19.5 (5); $273 \mathrm{~K}: 1.00$ (0), 3.53 (0.33), 11.0 (1), 18.5 (2), 24.8 (3), 27.1 (4), 28.1 (5). The conductivity of $\mathrm{NBu}_{4} \mathrm{PF}_{6}$ in the same conditions was $85 \mu \mathrm{S} \mathrm{cm}^{-1}$ at $193 \mathrm{~K}$ and $249 \mu \mathrm{S} \mathrm{cm}^{-1}$ at $273 \mathrm{~K}$.

Computational Studies. Geometry optimizations were performed at the PM3 semiempirical level with SPARTAN 02. ${ }^{25}$ No symmetry was imposed; however, most of the structures possess $C_{s}$ or $C_{2}$ symmetry (see the text). Optimizations were done employing the Hessian matrix computed at the PM3 level; the convergence criteria in geometry optimization for the maximum gradient component and the maximum change in a bond length were set to $10^{-5}$ au and $10^{-4} \AA$. The nature (true minima or transition structures) of all the stationary points found was determined by computing the Hessian matrix. To ascertain that the transition structures link the two expected minima, the eigenvector associated with the negative eigenvalue was followed in both directions (by minimizing two slightly distorted structures). Singlepoint energy computations at the B3LYP/6-31G(d,p) level were done with GAUSSIAN 03. ${ }^{26}$

Acknowledgment. The authors thank Basell Polyolefins for providing samples of bis(pentafluophenyl)borinic acid. P.M. and A.S. acknowledge Prof. Maurizio Sironi for the use of SPARTAN 02. Thanks are also due to Italian CNR (ISTM) for providing facilities for inert atmosphere and low-temperature experiments.

Supporting Information Available: Details on the NMR characterization, one table, and 13 figures. This material is available free of charge via the Internet at http://pubs.acs.org.

\section{OM061167P}

(25) SPARTAN 02; Wavefunction Inc.: Irvine, CA, 2002.

(26) GAUSSIAN 03 (revision C.02); Gaussian Inc.: Wallingford, CT, 2004 